\title{
Desnutrição intra-uterina e suas alterações no intestino delgado de ratos Wistar ao nascimento e após a lactação
}

\author{
In-uterus malnutrition and its changes in the small bowel of Wistar rats at birth and after lactation
}

\author{
Jocemara Gurmini'; William Augusto Casteleins Cecílioº ; Sandra Lúcia Schuler³; Márcia Olandoski; Lúcia de Noronha ${ }^{5}$
}

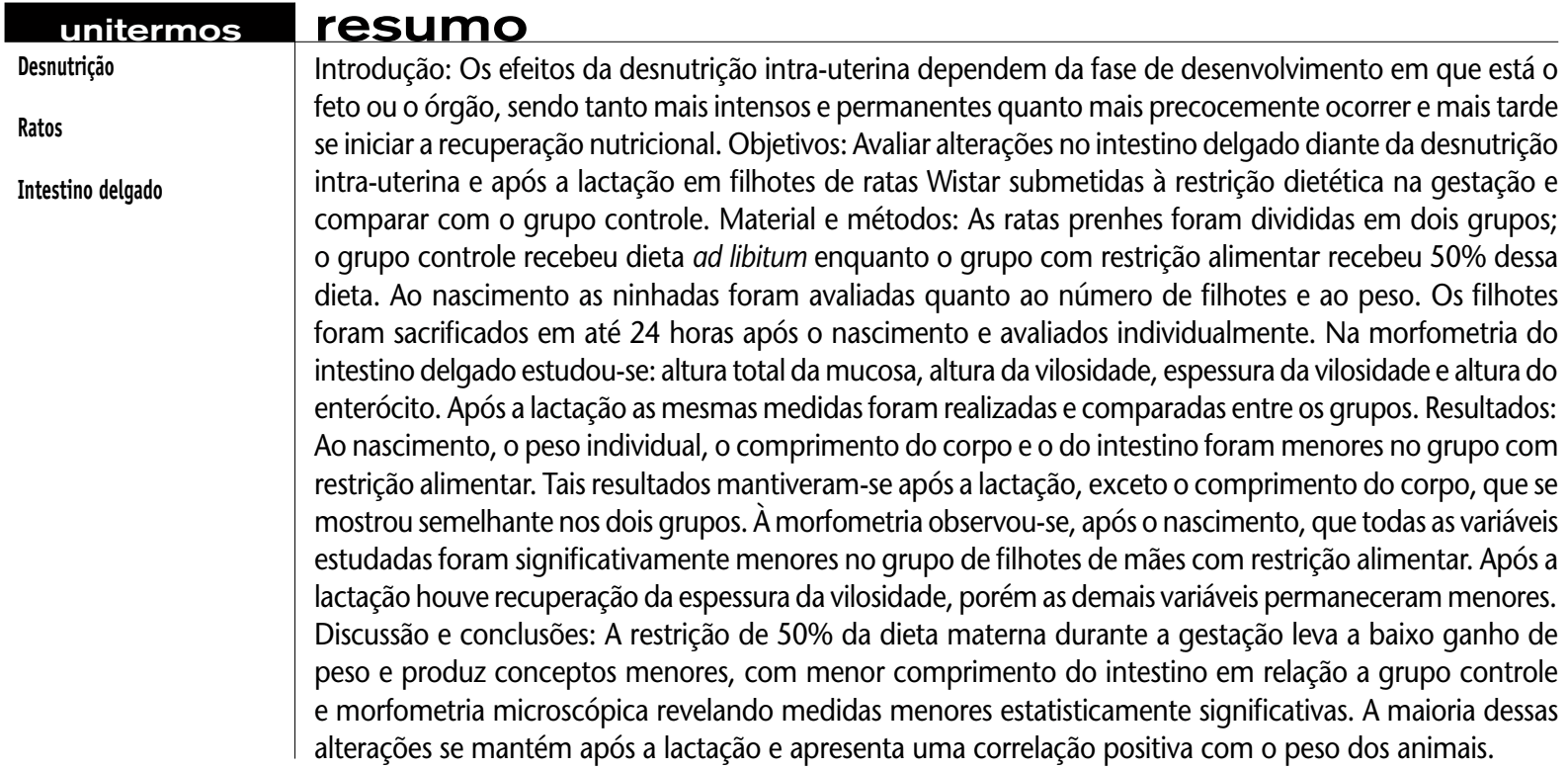

\section{abstract}

Background: The effects of in-uterus malnutrition depend on the developmental stage of the fetus or the organ, being more intense and permanent the earlier it happens and the later the nutritional recovery occurs. Objectives: Evaluate the changes in the small bowel regarding in-uterus malnutrition and after lactation in Wistar rats' pups that underwent pregnancy in dietary restriction and compare them to a control group. Material and method: The pregnant dams were divided into two groups; the control group received ad libitum diet whereas the food deprivation group had $50 \%$ of that intake. At birth, the litters were evaluated on the number of pups and their weight. Twenty-four hours after delivery, part of them was sacrificed and evaluated one at a time. In the intestine, the total height of the mucosa, the height of the villi, the height of the enterocyte and the thickness of the villi were studied by means of microscopic morphometry. The same measures were applied after lactation and the results were compared between groups. Results: After delivery, individual weight, body length and intestine length were lower in the pups whose mothers were fed with a restricted diet during pregnancy. Such results were sustained after lactation, except the body length, that was similar for both groups. All the varieties studied in the microscopic morphometry were significantly lower in the group of malnutrition mothers. After lactation, the thickness of the villi was recovered, although the other varieties remained low. Discussion and conclusion: This study indicates that a maternal diet restriction to $50 \%$ ad libitum induces lower maternal weight and produces smaller pups. The small intestinal length and the microscopic morphometry of the malnutrition group are diminished and the majority of the differences are maintained after the lactation period with positive correlation to the weight of the pups.

\section{key words} Malnutrition

Rats

Intestine, small

\footnotetext{
1. Médica pediatra com atuação em Castroenterologia Pediátrica; mestre em Ciências da Saúde pela Pontifícia Universidade Católica do Paraná (PUCPR).

2. Acadêmico de Medicina; estagiário do Laboratório de Patologia Experimental (LPE) do Centro de Ciências Biológicas e da Saúde (CCBS) da PUCPR.

3. Médica Pediatra com atuação em Gastroenterologia Pediátrica; mestranda em Ciências da Saúde pela PUCPR.

4. Professora-colaboradora do Curso de Pós-Graduação em Ciências da Saúde da PUCPR; mestre em Estatística.

5. Professora do Curso de Pós-Graduação em Ciências da Saúde da PUCPR; doutora em Patologia.

Artigo baseado na dissertação de mestrado intitulada Desnutrição intra-útero e suas alteraçôes no intestino delgado de ratos Wistar ao nascimento e após a lactação, apresentada no Curso de PósGraduação em Ciências da Saúde da PUCPR em julho de 2004.
} 


\section{Introducão}

A desnutrição é caracterizada por um desequilíbrio e/ou uma deficiência de nutrientes no organismo. Tais desequilíbrios são freqüentemente produzidos pela deficiência relativa de proteínas, carboidratos e gorduras como fontes de energia e micronutrientes. Essas deficiências são seguidas de alterações fisiopatológicas que primeiro traduzem-se em prejuízo funcional e, posteriormente, em danos bioquímicos e físicos. Inicialmente ocorre perda de peso que, quando se torna crônica, é seguida pela parada no crescimento.

Os efeitos da desnutrição intra-uterina dependem da fase de desenvolvimento em que está o feto ou o órgão, sendo os efeitos tanto mais intensos e permanentes quanto mais precocemente ocorrer a desnutrição e mais tarde for iniciada a recuperação nutricional. Embora em maior ou menor grau para os descendentes, a desnutrição intra-uterina, mesmo em fases diferentes da gestação, pode afetar o produto gestacional prejudicando o crescimento e o desenvolvimento dos diversos órgãos e aparelhos ${ }^{(8)}$.

Estudos com animais mostram que a desnutrição em períodos diferente da vida intra-útero pode resultar em recém-natos com tamanhos semelhantes, porém com alterações específicas sobre os órgãos. Acompanhando os mecanismos metabólicos compensatórios para proteger tecidos importantes, especialmente o cérebro, ocorre uma redistribuição do fluxo sangüíneo intra-útero. Esse mecanismo protetor leva ao prejuízo de alguns órgãos, como fígado e outras vísceras abdominais, alterando a composição corporal e diminuindo a secreção de hormônios que atuam no crescimento fetal(1-3).

\section{Objetivos}

Este trabalho tem como objetivo estudar os efeitos da desnutrição intra-uterina sobre o intestino delgado de ratos, ao nascimento e após o período de lactação, em filhotes de ratas submetidas a restrição dietética apenas durante a gestação, tendo como controles filhotes de ratas adequadamente nutridas. Objetiva especificamente: avaliar comparativamente as ratas-mães nutridas e com restrição alimentar quanto ao peso no início e no final da gestação; avaliar comparativamente as ninhadas de mães nutridas e com restrição alimentar quanto ao número de filhotes e peso ao nascimento; avaliar comparativa, morfológica e macroscopicamente os filhotes de mães nutridas e com restrição alimentar quanto a peso, comprimento do corpo e comprimento do intestino; avaliar comparativa, morfomé- trica e microscopicamente o intestino delgado de filhotes de ratas-mães nutridas e com restrição alimentar e verificar se existem diferenças morfológicas microscópicas no intestino delgado entre esses filhotes.

\section{Material e método}

Utilizaram-se 60 ratos Wistar (Rattus norvegicus albinus) adultos com 90 dias de vida, sendo 30 machos e 30 fêmeas, sem doença prévia. Inicialmente os ratos ficaram alojados em grupos de cinco animais do mesmo sexo por um período de adaptação de 48 horas, recebendo alimentação apropriada-padrão Nuvilab CR1 ${ }^{\circledR}$ e água ad libitum.

As fêmeas, todas nulíparas, com peso médio de $253,5 \mathrm{~g}$, foram agrupadas com machos na proporção 1:1, totalizando 30 casais, por um período de cinco dias. Os animais tinham livre acesso à ração-padrão comercial e à água durante essa fase do experimento. $\mathrm{O}$ sexto dia marcou o início dos controles de peso dos animais e da ração. As fêmeas grávidas ( $n=19)$ foram separadas dos machos, mantidas em gaiolas individuais e divididas em dois grupos: nutrido e desnutrido (dez animais no grupo nutrido e nove no grupo desnutrido).

A água foi mantida ad libitum para os dois grupos durante todo o experimento; a ração foi pesada e controlada diariamente; os animais, pesados a cada três dias até o parto. As medições foram realizadas no período da manhã. Foi feita uma média da quantidade de alimento ingerido pelo grupo nutrido em 24 horas e ao grupo desnutrido ofereceu-se metade desse valor até o dia do parto.

Após o parto, as mães foram pesadas, determinando o primeiro peso materno durante o período de lactação. A ninhada também foi pesada, verificando-se o número de filhotes e a média de peso dos ratos recém-nascidos por ninhada. As mães com restrição alimentar receberam uma quantidade de ração semelhante à do grupo nutrido logo após o nascimento dos filhotes. Quinze ratas e suas respectivas ninhadas puderam ser acompanhadas após 0 parto, sendo que as ratas-mães foram novamente pesadas com 23 dias de lactação.

Foram sacrificados filhotes nutridos e desnutridos em duas fases: logo após o nascimento e após o período de lactação. Na primeira fase foram sacrificados 30 filhotes: 15 nutridos e 15 desnutridos. Na segunda, que ocorreu entre o $23^{\circ}$ e $24^{\circ}$ dias de vida, foram sacrificados 21 filhotes: 9 nutridos e 12 desnutridos. Os filhotes foram pesados individualmente após o óbito. O corpo e o rabo de cada animal 
foram medidos com régua especialmente construída para o experimento, segundo técnicas de medida apresentadas por Hughes e Tanner (1970), ou seja, a distância entre a ponta do nariz e a ponta da cauda, com o animal deitado com a cabeça estendida em decúbito ventral sobre a régua.

Após o óbito, os órgãos abdominais foram removidos em bloco único, retirando-se o intestino (retificado e medido com fita métrica fixada sobre madeira) por liberação do mesentério. Três fragmentos do intestino delgado foram seccionados transversalmente (terços proximal, médio e distal) e o material foi mergulhado em formalina tamponada. Encaminharam-se as peças assim fixadas para estudo histopatológico, sendo que os fragmentos proximal, médio e distal foram analisados em conjunto.

Foi utilizado, para a análise histológica, microscópio óptico marca Olympus U-PMTVC com ocular de 10 aumentos e objetivas de 20 e 40 vezes, acoplado a um computador. As medidas foram feitas utilizando o programa ImageProplus ${ }^{\circledast}$ no aplicativo morfometria de linhas. Para o estudo foram escolhidas vilosidades bem orientadas, com porção basal, medial e apical aparentes e contínuas. Os seguintes parâmetros foram assim medidos:

- altura da vilosidade - dez vilosidades íntegras (aumento de 20x), traçando linha reta com o cursor do computador desde o centro da porção basal da vilosidade até o ápice;

- altura total da mucosa - dez vilosidades íntegras (aumento de 20x), traçando linha reta com o cursor entre o ápice da vilosidade e o limite inferior do fundo da cripta de Lieberkühn;

- espessura da vilosidade - dez vilosidades íntegras (aumento de 20x), medidas entre duas bordaduras estriadas e compreendendo a média das distâncias aferidas por retas traçadas com o cursor nas porções apical, medial e basal da vilosidade;

- altura do enterócito - 20 enterócitos medidos individualmente (aumento de 40x), traçando linha reta com o cursor entre a bordadura estriada e o final do núcleo. Para maior uniformidade foram medidas somente as células das partes lateral e medial da vilosidade.

Todas as variáveis do estudo foram expressas em médias e desvios padrões. Para comparar o grupo de mães nutridas com o grupo de mães desnutridas em relação ao resultado de cada variável, adotou-se o teste não-paramétrico de Mann-Whitney. Para comparar os grupos de animais nutridos e desnutridos em relação aos resultados de cada variável, adotou-se uma análise de variância considerando um modelo hierárquico. A associação entre variáveis foi analisada estimando-se o coeficiente de correlação de Pearson ou de Spearman, quando apropriado. A condição de normalidade foi verificada pelo teste de Shapiro-Wilks e em todos os testes um valor de $p<0,05$ indicou significância estatística.

\section{Resultados}

Ao comparar estatisticamente os grupos de ratas, podese observar que não existe diferença significativa $(p>0,05)$ entre os grupos de ratas-mães nutridas e com restrição alimentar em relação ao peso inicial, ao número de filhotes e ao peso da ninhada (Tabela 1). Isso evidencia que os grupos eram homogêneos em relação ao peso inicial, em relação ao número de filhotes gerados e ao peso total da ninhada. Quando se comparam esses mesmos grupos em relação a peso final, ganho de peso, peso no nascimento dos filhotes e peso médio da ninhada, ocorrem diferenças

Comparação entre os grupos de ratas nutridas e com restrição alimentar em relação às

Tabela 1 variáveis de estudo, mostrando 0 valor de $p$ para 0 teste näo-paramétrico de Mann-Whitney

\begin{tabular}{lccccc}
\hline \multirow{2}{*}{ Variáveis de estudo } & \multicolumn{2}{c}{ Grupo nutridas } & Grupo com restrição alimentar & Valor de p \\
& $\mathrm{n}$ & Média $\pm \mathrm{DP}$ & $\mathrm{n}$ & Média $\pm \mathrm{DP}$ & \\
Peso inicial $(\mathrm{g})$ & 10 & $218,86 \pm 15,3356$ & 9 & $225,38 \pm 14,2948$ & 0,3562 \\
Peso final $(\mathrm{g})$ & 10 & $265,7 \pm 35,4484$ & 9 & $226,01 \pm 23,2563$ & $\mathbf{0 , 0 0 7 6}$ \\
Ganho de peso (g) & 10 & $46,85 \pm 32,5413$ & 9 & $0,63 \pm 25,3122$ & $\mathbf{0 , 0 0 4 1}$ \\
Peso (g) ao nasc. (filhotes) & 8 & $233,05 \pm 16,1982$ & 7 & $183,9 \pm 13,2518$ & $\mathbf{0 , 0 0 0 3}$ \\
Número de filhotes & 8 & $8,13 \pm 1,5526$ & 7 & $9,14 \pm 3,1848$ & 0,6126 \\
Peso da ninhada (g) & 8 & $49,6 \pm 9,1643$ & 7 & $39,07 \pm 12,4998$ & 0,0939 \\
Peso médio da ninhada $(\mathrm{g})$ & 8 & $6,14 \pm 0,4679$ & 7 & $4,28 \pm 0,7387$ & $\mathbf{0 , 0 0 0 3}$ \\
\hline
\end{tabular}


significativas $(p<0,05)$ entre os grupos de nutridas e com restrição alimentar (Tabela 1).

Analisando-se a Tabela 1 percebe-se que, em todas as variáveis, o grupo com restrição alimentar apresenta médias menores do que o grupo de nutridas. Cabe comentar que a média de ganho de peso igual a 0,63g naquele grupo ocorreu porque muitas ratas tiveram perda de peso (igual a ganho negativo).

Os resultados apresentados nas Tabelas $\mathbf{2}$ e $\mathbf{3}$ se referem à avaliação morfológica macroscópica e morfométrica microscópica dos grupos de filhotes de mães nutridas e com restrição alimentar, estudados logo após o nascimento e ao final da lactação, respectivamente. Foi observado que o peso e o comprimento do intestino no grupo de filhotes das mães com restrição alimentar durante a gestação foi estatisticamente menor nos dois momentos, assim como a altura total da mucosa, a altura da vilosidade e a do enterócito. Apenas o comprimento do corpo e a espessura da vilosidade apresentaram-se estatisticamente menores no grupo submetido a restrição alimentar no momento zero. Após a lactação os resultados foram semelhantes nos dois grupos.

O coeficiente de correlação foi empregado para verificar se o peso e algumas variáveis apresentavam uma correlação direta (isto é, positiva e próxima de 1, sendo que quanto mais próxima de 1 mais se poderia prever o crescimento de uma variável qualquer, conhecendo o peso do animal). Foram encontradas associações positivas e estatisticamente significativas para algumas variáveis nos dois momentos,

Tabela 2

Comparação entre as variáveis de estudo nos grupos de filhotes de mäes nutridas e com restriçäo alimentar, logo após 0 nascimento, mostrando 0 valor de $p$ para 0 teste näo-

$\begin{array}{lccc}\text { Tabela } 2 & \text { paramétrico de Mann-Whitney } & & \\ & \text { Grupo nutrido } & \text { Grupo desnutrido } & \\ \text { Variáveis de estudo } & 2 \text { ratas-mães } & \text { 4 ratas-mães } & \text { Valor de p } \\ & 15 \text { filhotes } & 15 \text { filhotes } & \\ & \text { Média } \pm \text { DP } & \text { Média } \pm \text { DP } & <0,0001 \\ \text { Peso }(\mathrm{g}) & 6,56 \pm 0,66 & 4,22 \pm 0,77 & <0,0001 \\ \text { Corpo }(\mathrm{cm}) & 5,39 \pm 0,12 & 4,59 \pm 0,3 & <0,0001 \\ \text { Intestino }(\mathrm{cm}) & 23,46 \pm 1,35 & 17,84 \pm 1,44 & <0,0001 \\ \text { Altura total }(\mu \mathrm{m}) & 216,92 \pm 18,57 & 146,35 \pm 10,97 & <0,0001 \\ \text { Altura vilosidade }(\mu \mathrm{m}) & 184,87 \pm 20,69 & 112,84 \pm 12,97 & <0,0001 \\ \text { Espessura }(\mu \mathrm{m}) & 59,72 \pm 3,44 & 50,35 \pm 2,07 & <0,0001 \\ \text { Altura enterócito }(\mu \mathrm{m}) & 13,54 \pm 0,78 & 9,89 \pm 1,32 & \end{array}$

Comparação entre as variáveis de estudo nos grupos de filhotes de mães nutridas e com restriçăo alimentar após o final do período de lactação (23-24 dias de vida), mostrando 0

Tabela 3 valor de $p$ para 0 teste não-paramétrico de Mann-Whitney

\begin{tabular}{lccc} 
& Grupo nutrido & Grupo desnutrido & \\
Variáveis de estudo & 2 ratas-mães & 3 ratas-mães & Valor de $p$ \\
& 9 filhotes & 14 filhotes & \\
& Média $\pm \mathrm{DP}$ & Média $\pm \mathrm{DP}$ & \\
Peso $(\mathrm{g})$ & $50,35 \pm 4,21$ & $40,42 \pm 6,4$ & 0,0034 \\
Corpo $(\mathrm{cm})$ & $12,15 \pm 0,45$ & $11,18 \pm 0,59$ & 0,6994 \\
Intestino $(\mathrm{cm})$ & $87,08 \pm 1,06$ & $76 \pm 3,28$ & $<0,0001$ \\
Altura total $(\mu \mathrm{m})$ & $382,08 \pm 18,3$ & $317,25 \pm 27,19$ & 0,0040 \\
Altura vilosidade $(\mu \mathrm{m})$ & $268,73 \pm 12,78$ & $225,62 \pm 24,63$ & 0,0215 \\
Espessura $(\mu \mathrm{m})$ & $96,96 \pm 2,22$ & $96,45 \pm 10,04$ & 0,9261 \\
Altura enterócito $(\mu \mathrm{m})$ & $12,44 \pm 0,09$ & $10,81 \pm 0,78$ & 0,0122 \\
\hline
\end{tabular}


quando se analisam todos os filhotes juntos (Tabela 4). Porém, quando se analisam os filhotes de mães nutridas e desnutridas separadamente, essas correlações não estão tão claras, exceto para o comprimento do corpo e do intestino. Ou seja, podemos dizer que quando há um retardo de crescimento representado por baixo peso há também um retardo de crescimento do intestino dos animais no momento do nascimento. Essa correlação positiva se mantém no grupo dos desnutridos após a lactação, porém perde força, talvez porque o intestino já esteja próximo de atingir o seu tamanho. No grupo dos nutridos essa correlação não mais existe após a lactação, talvez porque o intestino já tenha atingido o seu tamanho, independente do crescimento do animal. Isso pode significar que existe um atraso no crescimento do intestino, não só em relação ao peso mas também em relação à idade dos animais (Tabela 4).

\section{Discussão}

Antes do acasalamento não houve diferença significativa quanto ao peso inicial das ratas, portanto a amostra foi considerada homogênea $(p>0,05)$. No final da gestação, o grupo de ratas com restrição dietética apresentou resultados estatisticamente menores, sendo que, em algumas ratas do grupo submetido a desnutrição, o peso ao final da gestação chegou a ser menor que o inicial. Esses resultados são semelhantes aos de alguns estudos da década de 1980 que verificaram a influência da desnutrição protéico-calórica em determinados períodos gestacionais ${ }^{(10,11)}$. Assim como no estudo de Tonete et al., onde foi relatado óbito durante o trabalho de parto no grupo desnutrido desde o início da gestação, no grupo com restrição alimentar do presente estudo ocorreram dois óbitos maternos em data próxima ao parto, sendo estas as ratas que apresentaram a maior perda de peso em relação ao peso do início da gestação(11).

O peso da ninhada aqui obtido foi maior no grupo de nutridas, porém sem significado estatístico $(p>0,05)$ devido à variação no número de filhotes em cada ninhada. Quando se compara o peso médio da ninhada, o grupo nutrido apresentou resultados maiores e com diferença estatística $(p$ $<0,05)$. Quanto ao número de filhotes, apesar de não haver diferença estatística entre a média do número de filhotes por ninhada, o grupo nutrido apresentou-se menor, discordando de alguns relatos da literatura. Young, Lee e Lebhental, em

Comparação entre 0 peso dos animais e as variáveis de estudo de todos os filhotes juntos, no dia 0 (logo após o nascimento) e no dia 23 (após o final do período de lactação), mostrando os Tabela 4 coeficientes de correlaçäo e os valores de $p$

\begin{tabular}{|c|c|c|c|c|c|c|c|}
\hline \multirow[t]{2}{*}{ Sacrifício } & \multirow[t]{2}{*}{ Variáveis } & \multicolumn{2}{|c|}{ Todos os filhotes } & \multicolumn{2}{|c|}{ Filhotes de mãe nutrida } & \multicolumn{2}{|c|}{ Filhotes de mãe desnutrida } \\
\hline & & $\begin{array}{l}\text { Coeficiente } \\
\text { de correlação }\end{array}$ & Valor de $p$ & $\begin{array}{l}\text { Coeficiente } \\
\text { de correlação }\end{array}$ & Valor de $p$ & $\begin{array}{l}\text { Coeficiente } \\
\text { de correlação }\end{array}$ & Valor de p \\
\hline \multirow{5}{*}{ Dia 0} & Peso x corpo & 0,92 & $<0,0001$ & 0,58 & 0,0235 & 0,52 & 0,0467 \\
\hline & Peso $\mathrm{x}$ intestino & 0,89 & $<0,0001$ & 0,49 & 0,0613 & 0,54 & 0,0357 \\
\hline & $\begin{array}{l}\text { Peso } \mathrm{x} \text { altura } \\
\text { total }\end{array}$ & 0,67 & $<0,0001$ & $-0,41$ & 0,1312 & $-0,44$ & 0,1014 \\
\hline & $\begin{array}{l}\text { Peso } \mathrm{x} \text { altura da } \\
\text { vilosidade }\end{array}$ & 0,66 & 0,0001 & $-0,45$ & 0,091 & $-0,47$ & 0,0786 \\
\hline & $\begin{array}{l}\text { Peso } \mathrm{x} \text { altura do } \\
\text { enterócito }\end{array}$ & 0,74 & $<0,0001$ & $-0,33$ & 0,2251 & $-0,23$ & 0,4051 \\
\hline \multirow{5}{*}{ Dia 23} & Peso x corpo & 0,94 & $<0,0001$ & 0,9 & 0,0011 & 0,84 & 0,0002 \\
\hline & Peso $\mathrm{x}$ intestino & 0,57 & 0,0043 & $-0,02$ & 0,9644 & 0,28 & 0,3237 \\
\hline & $\begin{array}{c}\text { Peso } \mathrm{x} \text { altura } \\
\text { total }\end{array}$ & 0,48 & 0,0207 & $-0,09$ & 0,8216 & 0,4 & 0,154 \\
\hline & $\begin{array}{l}\text { Peso } \mathrm{x} \text { altura da } \\
\text { vilosidade }\end{array}$ & 0,61 & 0,0018 & 0,1 & 0,8052 & 0,49 & 0,0722 \\
\hline & $\begin{array}{c}\text { Peso } \mathrm{x} \text { altura do } \\
\text { enterócito }\end{array}$ & 0,71 & 0,0002 & 0,49 & 0,1797 & 0,59 & 0,0274 \\
\hline
\end{tabular}


1987, obtiveram no grupo que recebeu $50 \%$ menos alimento durante a gestação um menor número de filhotes por ninha$\mathrm{da}$, com diferença estatisticamente significativa em relação ao grupo controle ${ }^{(14)}$. Um estudo mais antigo realizado por Zeman, em 1967, tentou determinar os efeitos da restrição protéica da dieta materna sobre os filhotes e a duração das alterações, concluindo, com relação à fertilidade, que a dieta com $6 \%$ de proteína manteve o número de filhotes por ninhada, porém os produtos tiveram uma média de peso corporal menor e uma vida média também menor ${ }^{(16)}$. Para alguns trabalhos da literatura o número menor de ninhadas no grupo com restrição protéica na dieta poderia ser secundário a aborto e/ou reabsorção fetal durante a gestação $0^{(11,13)}$. Em nosso estudo uma rata considerada prenhe inicialmente não evoluiu como tal e foi excluída. Para Young e Rasmussen, o número semelhante de filhotes entre ninhadas de mães nutridas e com restrição alimentar durante a gestação pode ser explicado pela ocorrência da restrição dietética apenas durante a gestação e não desde o período que antecede a idade reprodutiva. Esses autores encontraram um número menor de filhotes em ninhadas cujas mães haviam sofrido restrição dietética de $40 \%$ e $50 \%$ em relação ao grupo controle desde 28 dias antes do acasalamento ${ }^{(13)}$.

Duas ninhadas foram perdidas no grupo nutrido: uma por rejeição da mãe e outra por canibalismo. O óbito da ninhada é mais comum em grupos com restrição dietética e não no grupo nutrido, tendo como possíveis causas: a procura de alimento pela mãe, deixando de aquecer os filhotes ${ }^{(13)}$; filhotes fracos em uma ninhada grande, onde a competição pelo leite e a sucção débil impedem a alimentação(16); e o canibalismo(10).

O peso dos ratos submetidos à desnutrição intra-útero aqui obtido foi estatisticamente menor do que o peso dos filhotes de matrizes adequadamente nutridas $(p<0,05)$, resultado semelhante aos de outros autores ${ }^{(8,12)}$. No trabalho realizado por Tonete et al., os animais dos grupos controle e desnutridos na primeira fase da gestação nasceram com bom peso, enquanto $58 \%$ dos desnutridos na segunda fase da gestação e $96 \%$ do grupo desnutrido em toda a gestação apresentaram-se com peso inadequado ${ }^{(11)}$.

Em relação ao comprimento do corpo ao nascimento, encontraram-se poucas referências na literatura pesquisa$\mathrm{da}^{(5,16)}$. Foi observado neste estudo que, ao nascimento, os filhotes do grupo submetido à restrição dietética apresentavam não só o peso, mas também o comprimento do corpo menor em relação ao grupo controle, concordando com os resultados da literatura ${ }^{(10,11,14,16)}$. Acredita-se que as modificações mais significativas do peso ao nascimento ocorram no último trimestre de gestação, e que quando a desnutrição intra-uterina ocorre a partir do início da gestação, os produtos apresentam alteração tanto do peso quanto do comprimento do corpo.

Assim como no trabalho feito por Gutierrez et al., em 1988, o comprimento do intestino neste experimento foi estatisticamente menor no grupo dos filhotes de matrizes submetidas à restrição dietética durante a gestação $(p<$ $0,05)^{(4)}$. O peso dos animais após a lactação ainda apresentou-se estatisticamente menor no grupo de filhotes de mães com restrição alimentar $(p<0,05)$. Já o comprimento do corpo, apesar de ser maior nos filhotes de matrizes adequadamente nutridas, não apresentou diferença estatística entre os dois grupos $(p>0,05)$. Patricio, Nóbrega e Tonete, em 1984, acompanharam filhotes de ratas submetidas à restrição dietética em fases diferentes da gestação e adequadamente nutridos na lactação. O grupo de filhotes de mães com restrição alimentar durante toda a gestação ainda apresentava peso menor em relação ao grupo controle no $21^{\circ}$ dia de vida ${ }^{(8)}$. Resultados diferentes foram obtidos por Oliveira et al., que estudaram as alterações musculoesqueléticas causadas pela desnutrição intra-uterina com $50 \%$ de restrição na dieta e observaram evolução ponderal adequada dos ratos após a lactação(7). Younozai e Ranshaw, em 1973, avaliaram o crescimento corporal de filhotes de mães com $6 \%$ de proteína na dieta durante a gestação e prematuros, comparando-os com filhotes de mães alimentadas com dieta com $26 \%$ de proteína. Após o nascimento, os filhotes foram alimentados por mães de leite que receberam dieta com quantidade adequada de proteína e, ao final da lactação, o peso foi semelhante nos três grupos ${ }^{(15)}$.

Resultados discordantes foram encontrados em um estudo mais recente realizado por Weaver et al. Aos 21 dias os filhotes de mães com restrição protéica apenas durante a gestação não apresentaram diferença estatística de peso em relação ao grupo controle; já os filhotes de mães com restrição protéica na gestação e lactação e só na lactação pesaram $50 \%$ menos que os controles ${ }^{(12)}$. Os resultados referentes ao peso e ao comprimento do corpo no presente estudo demonstraram a recuperação do comprimento do corpo após a lactação. No trabalho realizado por Lemos sobre desnutrição intra-uterina e cicatrização da parede abdominal os produtos do grupo desnutrido foram menores ao nascimento, tanto no peso quanto no comprimento do corpo. No sétimo dia de vida não houve diferença no comprimento do corpo; já o peso manteve-se menor até o 14ํํㄹ de vida, revelando uma recuperação mais rápida do comprimento do corpo $^{(6)}$. 
Neste experimento, mesmo após o período de lactação com as ratas-mães recebendo dieta ad libitum, os filhotes de matrizes que passaram por restrição dietética apresentaram comprimento do intestino estatisticamente menor quando comparados ao grupo controle $(p<0,05)$. Em um dos estudos da literatura pesquisada, após o nascimento alguns filhotes foram trocados e amamentados pelas mães do outro grupo e os demais permaneceram com suas respectivas progenitoras. No $20^{\circ}$ dia de vida, o grupo de filhotes de mães com restrição alimentar na gestação e lactação apresentou o menor comprimento de intestino, seguido do grupo de filhotes de mães com restrição dietética na gestação e amamentados pelas mães controle. Outros dois grupos, formados por filhotes de mães nutridas na gestação e amamentados ou por mães com restrição alimentar ou por mães nutridas, apresentaram valores superiores aos dois primeiros, sugerindo a importância do fator nutricional durante a formação intra-uterina ${ }^{(14)}$. O estudo experimental de Weaver et al. analisou o comprimento intestinal no $21^{\circ}$ dia de vida e concluiu que os piores resultados foram encontrados no grupo de filhotes de mães com restrição protéica durante a gestação e a lactação, seguido do grupo formado por filhotes de mães sem restrição protéica na gestação mas com restrição na lactação, chamando a importância para a nutrição adequada no pós-parto ${ }^{(12)}$.

O grupo submetido à restrição dietética na gestação, em nosso experimento, apresentou valores estatisticamente menores $(p<0,05)$ da altura total da mucosa e da altura das vilosidades. Mesmo após a lactação, com as mães recebendo dieta ad libitum, os dois parâmetros ainda apresentaram resultados menores e com diferenças estatísticas. Relações diferentes logo ao nascimento e após a lactação foram encontradas na avaliação da espessura das vilosidades, que no dia 0 foram estatisticamente menores no grupo de filhotes de mães com restrição alimentar e após a lactação não apresentaram diferença estatística ( $p$ > $0,05)$. A altura do enterócito foi estatisticamente menor no grupo desnutrido intra-útero, tanto no nascimento quanto após a lactação.

Os modelos experimentais de desnutrição intra-uterina com dieta materna hipoproteica não seguem um padrão único quanto ao percentual de proteína ofertada. Um desses estudos tentou determinar as diferenças entre parâmetros do intestino delgado nos filhotes de mães alimentadas durante a gestação com dieta hipoproteica ( $4 \%$ caseína) e compará-los com um grupo controle que recebeu dieta adequada ( $24 \%$ caseína). Nos filhotes submetidos à desnutrição intra-útero os parâmetros foram reduzidos se comparados aos controles. As maiores diferenças entre os grupos ocorreram nos segmentos proximal e medial do intestino, onde o número de vilosidades por centímetro, a altura das vilosidades e o número de enterócitos foram mais afetados que no segmento distal. As diferenças desapareceram aos 12 dias nos filhotes que sobreviveram até essa data, exceto quanto ao número de enterócitos das vilosidades intestinais, possibilitando a esses animais déficits nutricionais irrecuperáveis, uma vez que a absorção intestinal depende do número de enterócitos e de sua capacidade absortiva ${ }^{(9)}$.

Resultados discordantes foram obtidos por um estudo mais recente que testou a hipótese de a desnutrição protéica no período pré e pós-natal ter efeitos duradouros sobre crescimento, estrutura e funcionamento dos órgãos do trato gastrintestinal. Foi observado, na avaliação da morfologia da mucosa intestinal aos 20 dias de vida, que as menores alturas das vilosidades foram encontradas nos filhotes cujas mães sofreram restrição protéica apenas na lactação, sendo inferiores às vilosidades das ratas submetidas à restrição protéica apenas na gestação. Os autores sugeriram que a restrição protéica pré-natal isolada não apresenta efeitos negativos duradouros sobre as dimensões e o crescimento do trato gastrintestinal(12).

Um dos trabalhos da literatura pesquisada estudou os efeitos da desnutrição em diferentes períodos gestacionais (primeira metade, segunda metade ou toda a gestação), observando que houve redução da altura das vilosidades nos três grupos. O melhor desempenho entre os desnutridos foi o do grupo que sofreu restrição dietética na primeira metade da gestação. A desnutrição intra-uterina afetou o tamanho do enterócito dos animais em nível significante em todos os momentos examinados. A desnutrição durante toda a gestação foi a que apresentou os piores resultados. Ao desmame não houve diferença entre os períodos em que ocorreu a desnutrição intra-útero, porém os valores das médias da altura dos enterócitos dos ratos que sofreram restrição dietética durante a gestação foram menores que os controles, concordando com o experimento aqui realizado( ${ }^{(8)}$.

Deve-se considerar que os tipos de restrição dietética aplicada aos estudos, por serem diversos, podem ser o determinante de alguns resultados discordantes. Em alguns modelos experimentais, o número de filhotes na ninhada foi reduzido, diminuindo a competição pelo alimento ${ }^{(12,7}$, 8). Talvez ninhadas numerosas impeçam a recuperação nutricional durante a lactação. No estudo realizado, o número de filhotes em algumas ninhadas submetidas à desnutrição 
superou o número de filhotes em ninhadas de nutridos, o que poderia ter atrapalhado o desenvolvimento daqueles filhotes durante a lactação.

\section{Conclusões}

Os filhotes de mães submetidas à restrição dietética na gestação apresentam peso, comprimento do corpo e comprimento do intestino menores, recuperando apenas o comprimento do corpo após a lactação, mas não atingindo o desenvolvimento alcançado pelos filhotes de mães nutridas. Além disso, a altura total da mucosa, a altura da vilosidade, a espessura da vilosidade e a altura do enterócito também foram comprometidas, apenas recuperando-se a espessura da vilosidade após o período de lactação. Essa comparação mostra que o filhote submetido à desnutrição durante a gestação, mesmo após a lactação, apresenta subdesenvolvimento.

Foi encontrada uma correlação positiva entre o peso dos filhotes e algumas medidas morfométricas do intestino, isto é, quanto maior o peso dos filhotes, maiores as medidas morfométricas do intestino quando se investigam todos os filhotes.

Quando se investigam os filhotes de mães nutridas e desnutridas separadamente, observa-se que aqueles filhotes desnutridos e com baixo peso ao nascer (não devidamente recuperado durante a lactação) apresentam as medidas morfométricas menores que as esperadas para sua idade $\mathrm{e}$ seu peso; a recuperação parcial das mesmas pode estar na dependência da recuperação do seu peso.

\section{Referências}

I. BARKER, D. J. In utero programming of chronic disease. Clin Sci, v. 95, n. 2. p. II $15-28,1998$

2. FALL, C. H. D. et al. Micronutrients and fetal growth.J Nutr, v. I33, 5 Suppl 2, p. I747S- I756S, 2003.

3. GODFREY, K. M.; BARKER, D. J. Fetal programming and adult health. Public Health Nutr, v. 4, n. 2, p. 61 I-24, 2001.

4. GUTIÉRREZ, J. M. et al. Efectos de la malnutrición in útero y en la lactancia sobre diversos parámetros del intestino delgado de rata. Rev Esp Fisiol, v. 44, n. 4, p. 4I3-22, 1988.

5. HUGGES, P. C. R.; TANNER, J. M. A longitudinal study of the growth of the Black-hooded rats: methods of measurement and rates of growth for skull, limbs, pelvis, nose-rump and tail lengths. J Anat, v. 106, n. 2, p. 349-70, 1970.

6. LEMOS, I. C. M. C. Influência da desnutrição intra-uterina na cicatrização da parede abdominal de ratos lactentes avaliada mediante estudo tensiométrico e da morfometria do colágeno. Curitiba, 2002. Tese (doutorado em Cirurgia) - Setor de Ciências da Saúde, Universidade Federal do Paraná.

7. OLIVEIRA, F. L. C. et al. Desnutrição energética intra-uterina em ratos: alterações músculo-esqueléticas na $I^{\mathrm{a}}$ e $2^{\mathrm{a}}$ gerações. J Pediatr, v. 75, n. 5, p. 350-6, 1999.

8. PATRÍCIO, F. R. S.; NÓBREGA, F. .;TONETE, S. S. Q. Desnutrição intra-uterina em diferentes períodos de gestação em ratas: estudo do intestino delgado proximal ao nascimento e durante a recuperação nutricional. Rev Paul Pediatr, v. 2, n. 8, p. 43-52, 1984.
9. SHRADER, R. E.; FERLATTE, M. I.; ZEMAN, F. J. Early postnatal development of the intestine in progeny of protein-deprived rats. Biol Neonate, v. 31, n. 3-4, p. 181-98, 1977.

10.TONETE, S. S. Q. et al. Desnutrição intra-uterina em ratos. II. Estudo do peso e mortalidade do produto da concepção. Arch Latinoam Nutr, v. 33, n. I, p. 109-25, 1983 a.

I I. TONETE, S. S. Q. et al. Desnutrição intra-uterina em ratos. I. Repercussões no ganho de peso, tempo de gestação e no número de recém-nascidos. Arch Latinoam Nutr, v. 33, n. I, p. 96-108, 1983b.

12.WEAVER, L.T. et al. Effects of protein restriction in early life on growth and function of the gastrointestinal tract of the rat. J Pediatr Gastroenterol Nutr, v. 27, n. 5, p. 553-9, 1998.

I 3.YOUNG, C. M.; RASMUSSEN, K. M. Effects of varying degrees of chronic dietary restriction in rat dams on reproductive and lactational performance and body composition in dams and their pups. Am J Clin Nutr, v. 4I, n. 5, p. 979-87, 1985.

I4. YOUNG, C.M.; LEE, P. C.; LEBENTHAL, E. Maternal dietary restriction during pregnancy and lactation: effect on digestive organ development in suckling rats. Am J Clin Nutr, v. 46, n. I, p. 36-40, 1987.

15. YOUNOSZAI, M. K; RANSHAW, J. Gastrointestinal growth in the fetus and suckling rat pups: effects of maternal dietary protein. J Nutr, v. 103, n. 3, p. 454-61, 1973.

16. ZEMAN, F. J. Effect on the young rat of maternal protein restriction.J Nutr, v. 93, n. 2, p. 167-73, 1967
Endereço para correspondência

Lúcia de Noronha

Laboratório de Patologia Experimental

Centro de Ciências Biológicas e da Saúde - Campus 1

Pontifícia Universidade Católica do Paraná

Rua Imaculada Conceição, 1155 - Prado Velho

CEP 80215-901 - Curitiba-PR

Tel.: (41) 271-1515, ramal 2264

Fax: (41) 271-1624 